\author{
Alcileide Cabral Nascimento
}

Universidade Federal Rural de Pernambuco, Recife, PE, Brasil

\title{
A Cruzada Feminista Brasileira e a Cultura Política em Pernambuco (1927-1932)
}

Resumo: Este artigo investiga a importância da Cruzada Feminista Brasileira, criada por Martha de Hollanda em 1931, na construção de uma nova cultura política feminista em que as mulheres debatem na imprensa a desigualdade de gênero e defendem direitos políticos igualitários entre os anos 1927 e 1932. A Cruzada Feminista Brasileira fez uso estratégico dos jornais como principal veículo de comunicação de massa no momento em que se instituíam o sujeito feminino do direito e a opinião pública por meio dos periódicos. As feministas expandiram as exigências da equidade, questionaram as diferentes assimetrias da República liberal e pouco democrática, contestaram a naturalização da diferença entre os sexos e lutaram pela ampliação da cidadania e da democracia em solo pernambucano. Do legado dessas lutas feministas, pouco conhecido na História, todas nós somos beneficiárias.

Palavras-chave: Cruzada Feminista Brasileira; Martha de Hollanda; Cultura Política Feminista.

\section{Introdução}

O regime republicano no Brasil parecia dar concretude aos acalentados e eufóricos sonhos de um país melhor, que foi capaz de romper com a escravidão e transitar para uma nova forma de governo inspirada na democracia, ainda que aos moldes liberais. Uma das questões que se colocava era como a jovem República, com diferenças estruturais profundas, iria transformar sua população tão diversa em cidadãos e cidadã̃. Nesse novo cenário, impunha-se a redefinição do público e do privado, como fez o Estado ao laicizar o casamento, impor o registro civil e, em 1916, promulgar o Código Civil republicano (Elias SALIBA, 2002, p. 294). Contudo, a presença do povo nas ruas como um novo e definitivo personagem da cena política, formado pelas classes média e trabalhadora urbanas, deu formato e cor à cultura política que nascia com a República (Hebe MATTOS, 2012, p. 92) e com a qual as mulheres instrumentalizaram suas reivindicações ao novo regime. As mulheres,

\section{(c) (†)}

Esta obra está sob licença Creative Commons. 
algumas declaradamente feministas, tiveram uma atuação importante na luta pela ampliação da noção e dos direitos da cidadania, pois alijadas estavam do jogo político por não serem consideradas cidadãs.

Mesmo sem direito ao voto, as mulheres discutiam e faziam política, aprendendo a se movimentar nesse cenário. Tornaram-se atrizes de suas histórias, rompendo com séculos de sujeição, ao mesmo tempo em que saíam da condição de coadjuvantes. Fizeram mobilizações em prol do voto feminino, como a marcha realizada por Leolinda Daltro e Gilka Machado nas ruas do Rio de Janeiro, em 1917 (Céli PINTO, 2003, p. 18-19; Schuma SCHUMAHER; Érico Vital BRAZIL, 2000, p. 318-320). Estavam nas artes visuais, na dança e nos teatros, como Anita Malfati e Eros Volúsia (Soraia SILVA, 2007). Reinventavam seus corpos, como as melindrosas, que inovavam no uso do cabelo curto, na expressiva maquiagem, nas saias acima do joelho e na depilação das pernas (Alcileide NASCIMENTO; Alexandre MELO, 2014, p. 6-20). Ocupavam as ruas e nelas transitavam para trabalhar, para o flerte, para o lazer, para a arte. Respiravam a cultura urbana com ousadia, apesar das cantilenas contrárias a essa mulher moderna. E continuaram o esforço de fundar associações políticas, como a criação da Liga para Emancipação Feminina Intelectual da Mulher, sob a liderança de Bertha Lutz, em 1919 (Rachel SOIHET, 2006, p. 31). Aos poucos, iam constituindo uma cultura política de feição feminista.

Mas quais os significados da nova cultura política que emergiu com a República? É possível afirmar que nascia, nesse cenário, uma cultura política feminista? Segundo Serge Berstein "[...] no interior de uma nação existe uma pluralidade de culturas políticas, mas com zonas de abrangências que corresponde à área dos valores partilhados" (BERSTEIN, 1988, p. 354). Pode-se admitir, ainda segundo o autor, "[...] que, no primeiro terço do século XX, a cultura política republicana desempenhou um papel dominante" para vários grupos políticos (BERSTEIN, 1988. p. 354). Assim, o conceito de cultura políitica, na perspectiva de Rodrigo Motta e Berstein, pode ser caracterizado "[...] como o conjunto de valores, tradições, práticas e representações políticas partilhado por determinado grupo humano, e tendo como objeto fenômenos políticos" (MOTTA, 2009, p. 21.), grupos esses que possuem uma leitura comum do passado e uma projeção sobre o futuro em termos de sociedade (BERSTEIN, 1988, p. 351).

Nesse sentido, entendo que as feministas, em sua maioria, mulheres letradas, formadas e com profissão, vão aos poucos se apropriando da cultura política republicana, dessas novas práticas de reivindicações e de debates, de redefinição do espaço público e privado, de constituição de organizações políticas, de realização de passeatas nas ruas, ao uso da imprensa escrita, como novas searas do debate público por seus direitos. Vão assim constituindo uma cultura política feminista, problematizando discursivamente as relações de gênero, as desigualdades abissais entre homens e mulheres ao afirmarem que essas desigualdades e a pretensa superioridade masculina não pertencem à natureza humana, mas à cultura, que exclui as mulheres da educação e das oportunidades. Nesse campo de luta, onde as fronteiras entre o público e o privado se diluem, as feministas fazem um esforço de constituir seus próprios valores e sua visão de mundo. $O$ projeto de sociedade que propunham rompe com o patriarcado (sobre o patriarcado cf.: NEUMA AGUIAR, 2000) e, nesse sentido, parecem mesmo construir uma utopia onde as mulheres anunciam novos valores e novos modelos (Mariette SINEAU, 1994, p. 73), uma sociedade igualitária entre homens e mulheres, onde predomine a cultura da paz num mundo marcado pela Primeira Guerra Mundial. Eis como exemplo a plataforma de ações da Federação Pernambucana para o Progresso Feminino, que repetia ipsis litteris o que a sua congênere nacional, a Federação Brasileira para o Progresso Feminino (FBPF), havia estabelecido, "[...] 7. Estreitar os laços de amizade com os demais países americanos, a fim de garantir a manutenção perpétua da paz e da justiça no Hemisfério Ocidental" (Ida Souto UCHÔA, 1931). 
Se Motta está certo quando assinala que, ao se tratar de cultura política, temos que ter em mente as "[...] normas, valores, etc, razoavelmente arraigados, estruturados, quando se estabelecem tradições que são reproduzidas por várias gerações" (MOTTA, 1996, p. 95), é possível sustentar que as mulheres não estavam arando solo virgem, não inventaram uma nova maneira de se expressar publicamente, mas se apropriaram dessa atmosfera republicana em que se discutia e se fazia política - e o fizeram numa perspectiva feminista, afastando-se dos valores patriarcais, que as reduziam às tarefas da reprodução no espaço privado e privilegiavam o domínio e a superioridade dos homens. Sem dúvida, a política ganhou as ruas, as praças, os jornais, como diagnosticou Mattos. As mulheres instrumentalizaram esses lugares de fala e de visibilidade para discutir e debater seus direitos até então negados, para afirmar que a maternidade não as impediriam do exercício político, pois acreditavam que podiam mudar as regras do jogo em pleno pulsar da experiência e dos combates republicanos em território brasileiro.

Vale ressaltar o desenvolvimento de um novo jornalismo nesse período, como aponta Nicolau Sevcenko, seja do ponto de vista do conteúdo, das técnicas de impressão e edição, que somado às revistas mundanas, intensamente ilustradas, "[...] tornam-se mesmo a coqueluche da nova burguesia urbana [...] Cria-se assim uma 'opinião pública' urbana, sequiosa do juízo e da orientação dos homens de letras que preenchiam as redações" (SEVCENKO, 1985, p. 94-95). Nesse campo, entram as mulheres: intelectuais, poetisas, professoras, advogadas, escritoras, engenheiras, na batalha simbólica para formar opiniões sob a ótica feminista. ${ }^{1}$

Os anos 20 fazem eclodir os impasses da república oligárquica e apontam para rupturas viscerais em busca de novos caminhos políticos e artísticos para o País: a fundação do Partido Comunista do Brasil, a realização da Semana de Arte Moderna, o debate da imprensa negra ou dos grupos culturais negros no Rio de Janeiro e em São Paulo, a movimentação operária e as greves operárias em várias capitais brasileiras, as insurreições militares tenentistas em São Paulo, o cangaço no Nordeste, movimentos que põem em cheque as alianças estabelecidas entre as oligarquias estaduais e as práticas coronelísticas (MATTOS, 2012, p. 120-129).

Segundo o abaixo-assinado da Federação Brasileira para o Progresso Feminino, enviado ao Senado Federal em 1927, o "[...] recenseamento de 1920 acusa[va] mais de um milhão de mulheres que exercem ofícios e profissões" (SCHUMAHER; BRAZIL, 2000, p. 220). Portanto, "[...] o voto não deve[ria] ser nem privilégio e nem recompensa que se dê aos cidadãos altamente especializados para exercerem essa função. É uma obrigação de todos" (SCHUMAHER; BRAZIL, 2000, p. 220). Mas a República, como se sabe, não era de todos/as e nem para todos/as. Fora abocanhada por grupos políticos que se revezavam no poder, entre os estados de São Paulo e Minas Gerais, com apoio de parte das oligarquias estaduais. Assim, o movimento civil-militar de 1930, ao romper como o pacto oligárquico da República "café com leite", abriu espaço para novas demandas relacionadas aos direitos civis e políticos. Discutia-se com paixão e urgência uma nova cidadania e a imperiosa necessidade da reforma eleitoral, e as mulheres aproveitaram e fizeram uso estratégico da imprensa para formar e fomentar opiniões sobre seus direitos, até então negados.

Esse debate alcança o Recife. Algumas mulheres, de famílias abastadas, formadas, escritoras, poetisas, professoras, têm nos jornais e nas revistas um canal de expressão de seus questionamentos e suas inquietações. Ademais, começam a se articular com o

' No Recife, as mulheres publicavam no Helios, n'O Lyrio, n'A Grinalda, n'O Myosote, além de inserções nos jornais. (NASCIMENTO; Noêmia LUZ, 2012. p. 126-149). 
movimento feminista do Rio de Janeiro, liderado por Bertha Lutz. Essa movimentação dá ensejo à criação, em 1931, de duas organizações feministas na capital pernambucana: a Cruzada Feminista Brasileira, sob a liderança de Martha de Hollanda (Alcileide NASCIMENTO, 2015, p. 1-1 1), e a Federação Pernambucana para o Progresso Feminino, sob o comando de Edwiges de Sá Pereira (NASCIMENTO, 2013, p. 41-57).

Em uma das missivas, datada de 1927, Edwiges, ainda em tom de muita formalidade com a feminista carioca, ao cumprimentar-Ihe como "Prezada e distinta D. Bertha Lutz", diz que aguarda a remessa dos novos Estatutos da Federação Brasileira, e "[...] que se encontra às ordens para o que for preciso fazer" sob a orientaçẫo da "[...] ilustre patrícia é-me grato e honroso" (SÁ PEREIRA, 13/04/1927) Nessa carta, pergunta: "Quem é a representante de Pernambuco, segundo a reforma dos Estatutos?", o que demonstra o quanto essa questão não estava definida. Embora se colocasse à disposição para a causa, sugeria que seria importante a presença de Bertha em Pernambuco "[...] para despertar entusiasmos, soerguer energias, agremiar para a grande causa tanta cooperação útil, tanta operosidade latente que o mundanismo desvia e absorve. [...] Com o auxílio oficial e o concurso da imprensa, completariam o cerco ao indiferentismo, ao ceticismo indígena" (SÁ PEREIRA, 13/04/1927).

Ainda em 1928, morando em Vitória de Santo Antão, cidade da Zona da Mata Sul pernambucana a $51 \mathrm{~km}$ da capital, Martha de Hollanda escreve a Carmem Portinho, secretária da Federação Brasileira, respondendo-Ihe ao convite que recebeu para associarse à Federação. É de se presumir que o convite era para Martha filiar-se à futura Federação Pernambucana, e não à nacional, tendo em vista a sondagem feita a Edwiges de Sá um ano antes, mas a jovem Martha diz que tinha o intento de fundar um "[...] núcleo feminino de propaganda e educação no Recife" para onde se mudaria após o casamento (HOLLANDA, 29/07/1928).

Nesse sentido, sugeria que seria "[...] interessante uma aproximação de interesses que se poderia resolver criando uma sociedade equiparada ou ainda uma filial da Federação Brasileira" (HOLLANDA, 29/07/1928). É uma carta muito diferente da enviada por Edwiges. Além da digressão literária que faz, a feminista tece uma pequena autobiografia, fala de seus projetos de criar uma revista que receberia o nome da Mulher Brasileira e diz que gostaria de contar com a colaboração das "[...] companheiras da jornada feminista", reportando-se a Bertha Lutz e a Carmem Portinho. Despede-se de forma efusiva, como era próprio de sua personalidade: "[...] com todos os meus beijos, sou a companheira incendiária" (HOLLANDA, 29/07/1928). Não se sabe dos motivos de Bertha Lutz para declinar do convite feito a Martha, mas também não é difícil imaginar a escolha que fez por Edwiges de Sá, mais discreta, mais madura e mais conservadora nas opiniões e atitudes em relação ao debate da cidadania política para as mulheres.

Portanto, o ano de 1931 é chave para se perceber que o movimento feminista em Pernambuco nasce mesmo cindido. A unidade, como gostaria de ver Bertha Lutz, nunca existiu. São duas mulheres fortes, carregando nomes tradicionais de suas famílias, ambas da Zona da Mata Sul, com diferença de idade entre elas, escritoras conhecidas e com inserção nos meios intelectuais, como educadoras e poetisas que eram. Eis por que o nome da associação é mesmo Cruzada Feminista Brasileira. ${ }^{2}$ Como Martha entendeu que o apoio da FBPF foi dado à sua adversária política e como já tinha afirmado em carta a Carmem Portinho, criou em Pernambuco uma "sociedade equiparada" à Federação Brasileira para o Progresso Feminino e remeteu para essa instituição seus estatutos (HOLLANDA, 29/07/1928).

${ }^{2}$ No Dicionário Crítico das Escritoras Brasileiras, há informação de que Martha de Hollanda fundou a Cruzada Feminista Pernambucana. É um equívoco. O nome é mesmo Cruzada Feminista Brasileira. Cf. Nely Novaes COELHO, 2002. p. 480.

4 Revista Estudos Feministas, Florianópolis, 26(2): e44481 
Em 31 de maio de 1931, Martha de Hollanda reuniu um grupo de amigas, escritoras e poetisas em sua casa. Nessa ocasião, elas criaram a Cruzada Feminista Brasileira ( $A$ Notícia, 1931, p. 1; A Noite, 1931, p. 1). No início de julho, as jovens feministas vão até a redação do periódico $A$ Notícia e posam para uma foto histórica: nove mulheres que dão asas, imaginação e ação à Cruzada. Ao mesmo tempo, divulgam as novas adesões, sobretudo de professoras, à associação (A Notícia, 1931, p. 1). Mas qual o significado da palavra cruzada? Segundo Aurélio Ferreira, no sentido figurado assinala "[...] campanha de propaganda em defesa de certos interesses, princípios ou ideias" (1986, p. 504). Era uma campanha, era uma causa, e, por vezes, Martha de Hollanda pintava com tons religiosos esse enfrentamento com homens e mulheres, incrédulos, que não acreditavam no potencial das mulheres como se pode observar no seu discurso de posse:

[...] Formemos, com a Cruzada Feminista Brasileira, o nosso campo de batalha, de onde procuramos dizer: voltamos e queremos ficar! [...] A Cruzada Feminista Brasileira será a mocidade de nossa velhice! A Atlântida encantada do nosso ideal, que terá que existir... [...] Minhas companheiras: trabalhemos por nós e para nós. Não desanimeis. Somos poucas, mas lembrai-vos que era pequenino o número de discípulos que espalhou a doutrina de Jesus (A Notícia, 1931, p. 1).

As feministas da Cruzada levaram mais três meses para definir os estatutos, e em 12 de novembro daquele mesmo ano foi empossada a diretoria: presidente, Martha de Hollanda; vice-presidente, Auri Moura; oradora, Heloísa Chagas; oradora adjunta, Juracy Soes; primeira secretária, Celeste Dutra; segunda secretária, Jacyra Goes; tesoureira, professora Antônia Maranhão; bibliotecária, Silvia do Passo; procuradoras, farmacêutica Antônia Martins e professora Edmée Barbosa (A Notícia, 1931, p. 3). Organizada a Cruzada Feminista e eleita sua diretoria provisória, foi aclamada presidente de honra Edwiges de Sá Pereira (A Notícia, 1931, p. 1), "[...] elemento dos mais significativos na vida intelectiva do Nordeste", segundo Martha de Hollanda (HOLLANDA, [s.d]). Em seguida, definiram os principais objetivos e declararam sua filiação à Federação Brasileira para o Progresso Feminino ( $A$ Notícia, 1931, p. 1). Mas Edwiges não apenas declinou do convite de ser presidente de honra da Cruzada, como informou que estava na condição de delegada da Federação Brasileira, empenhada na fundação de uma filial em Pernambuco, "insistindo então" que o grupo de Martha se filiasse a ela, "[...] para evitar os dissídios tão inconvenientes aos ideais coletivos", o que não foi possível (Notas Biobibliográficas de Edwiges de Sá Pereira.). As duas lideranças feministas em Pernambuco não pactuam, e cada uma, seguindo estratégias políticas próprias, passa a trabalhar, divulgar e arregimentar mais sócias para suas organizações e a fomentar a luta pela conquista da cidadania política.

Em carta à Bertha Lutz, Martha expunha seu ponto de vista e seu posicionamento, mas acreditava que essa divergência não teria muito relevo e que, mantendo-se os princípios e a "primogeneidade" da sua ideia, colocava-se pronta para "[...] colaborar, coadjuvar quaisquer novas sociedades que apareçam para nossa defesa moral, social ou política" (HOLLANDA, [s.d.]). Como se sabe, essa divergência entre as duas lideranças feministas teve, sim, muito relevo. O movimento feminista organizado em Pernambuco começa cindido, portanto, em duas frentes, e a FBPF apoiou publicamente sua congênere em solo pernambucano, e não a Cruzada Feminista Brasileira. Apesar de não receber apoio político da Federação Brasileira para o Progresso Feminino, a Cruzada ganhou concretude e visibilidade em Pernambuco. Nesse sentido, cabe investigar: a que se propunha a Cruzada? À que mulheres se dirigia? Qual era o alcance de sua proposta? Que estratégias políticas foram colocadas em prática? 


\section{A Cruzada Feminista Brasileira na luta pelos direitos políticos para as mulheres}

A imprensa teve papel fundamental nesse momento, como já foi assinalado. É o grande púlpito público da palavra e da imagem (Ana MARTINS; Tânia LUCA, 2006; Marialva BARBOSA, 1997, p. 87-102). A rede de intelectuais e de amigos que Martha de Hollanda tinha, facilitou, por certo, a intensa instrumentalização da mídia impressa e falada, na capital pernambucana, aos propósitos políticos da Cruzada. O que se vê é o combate, a batalha discursiva em prol dos direitos femininos por um lado e a propaganda desse ideário por outro, faces de uma mesma moeda. Some-se ainda o fato de que as notícias não fincam raízes apenas nesse rincão da nação. Os jornais do Rio de Janeiro noticiam com frequência os feitos da Cruzada e publicizam as imagens de sua principal líder ( $A$ Noite, 1931, p. 2; Jornal do Brasil, 1931, p. 3; Diário da Noite, 1931, p. 3).

A Notícia, periódico que abertamente apoiava a Cruzada, publica o programa da associação:

a) Elevar o nível intelectual e social da mulher nordestina, assegurando-lhe todos os direitos e promovendo-lhe a instrução necessária para a conquista de seu justo lugar nas sociedades civilizadas; b) assegurar as suas prerrogativas civis e constitucionais, facultandoIhes as garantias legislativas concernentes ao seu trabalho e as medidas protetoras às mães e à infância; c) estimular o espírito de organização, orientando-a nos problemas que, diretamente ou indiretamente, possam interessar-lhe, estendendo e ampliando a sua esfera de ação a todos os círculos civis e políticos; d) provocar o intercâmbio intelectual com as demais nações, a fim de que, pela sua ação homogênea e segura, seja mantida a paz e a tranquilidade do mundo (A Notícia, 1931, p. 1).

O conteúdo do programa é, efetivamente, político. A instrução é a via estratégica para a conquista ampla da cidadania e dos direitos civis, sociais e políticos. Embora se autodeclarasse como uma organização nacional, o conteúdo programático revela que o alcance geográfico era mesmo o Nordeste, ao nomear a "mulher nordestina" como sujeito de direitos; apesar desse lugar de pertencimento, essa região está em plena formação imagética e discursiva, como assinala Durval Albuquerque Jr. (2009). Ao considerar a instrução como ação transversal do programa, pensava-se como a via que possibilitaria a mulher conquistar "[...] seu justo lugar nas sociedades civilizadas". Mas o que é esse "justo lugar"? O que está implícito nessa questão? A ideia da injustiça do sistema parece ser uma das chaves para entender o embate das feministas com a República, tão pouco democrática. Essa plataforma de ações não divergia das diretrizes da Federação Brasileira (Estatuto da Federação Brasileira para o Progresso Feminino). Contudo, vincula a instrução à política como campos de aproximação, de convergência e de dependência. A instrução, nesse sentido, é terreno fértil para outras conquistas. É luz para trilhar a conquista da cidadania social, trabalhista e civil.

Nesse fluxo de opiniões, Martha de Hollanda publica um artigo no qual conclama as mulheres brasileiras à luta pelos direitos legais. Segundo a feminista, embora a Carta Magna expresse que "[...] todos são iguais perante a lei", na prática existem duas classes diferentes: a dos homens, "[...] para os quais estão abertas todas as portas"; e a das mulheres, "[...] escrava e servil às quais são negados todos os direitos e prerrogativas legais" (A Notícia, 1931 , p. 3). Em seu combativo discurso, afirma categoricamente que "[...] não há fundamento jurídico ou biológico que justifique o grande atentado" (A Notícia, 1931, p. 3). Recusa assim a essencialização das diferenças e desigualdades de gênero com base na natureza e na justiça, bem como fundamenta uma concepção de sociedade sob nova ótica. Se não são concedidos direitos às mulheres, também deveriam isentá-las de responsabilidades criminais.

6 Revista Estudos Feministas, Florianópolis, 26(2): e44481 
E compreende que, em nenhum momento, a Constituição fez essa distinção. E não fez mesmo. As consecutivas negações aos pedidos de alistamento em várias cidades do País se devem à livre interpretação de magistrados pelo Brasil afora, alegando que a mulher deveria ocuparse dos deveres da casa ( $O$ deferimento ou não dos pedidos de alistamento de mulheres são frequentemente debatidos na imprensa. Ver Branca Moreira Alves, 1980. p. 119).

Para Martha, a mulher que pensa e deseja sua emancipação política e moral não está desintegrando a família. Torna-se, apenas, consciente de seus deveres, dentre os quais avulta a obrigação do lar, onde se forma o homem e têm origem todas as civilizações (A Notícia, 1931, p. 3). Para referendar seu argumento, demonstra que o famoso jurista Clóvis Beviláqua, ${ }^{3} \mathrm{com}$ "[...] a fortaleza do seu prestígio e do seu saber", foi categórico ao afirmar que não existe essa distinção no art. 70 da Constituição brasileira. Para Beviláqua, "[...] A lei abrange o homem e a mulher, porque ambos são cidadãos" (A Notícia, 1931, p. 3). Declaração similar foi feita também pelo Congresso Jurídico do Instituto da Ordem dos Advogados, que entendia que a Constituição não proibia à mulher o exercício dos direitos políticos (A Notícia, 1931, p. 3).

Em síntese, em nome da Cruzada Feminista Brasileira, declara que as mulheres: não querem prejudicar o homem, mas ser companheiras conscientes de seu labor e de sua vida, e não suas escravas, submissas de sua vontade; almejam liberdade sem restrição; querem reconhecimento do trabalho sem distinção de sexo; desejam a evolução natural da sociedade, e não a revolução social; querem direitos políticos para intervir na vida do País (A Notícia, 1931, p. 3). Não há dúvida de que seu discurso rompia com a dominação masculina, ao mesmo tem em que se constitui como base de uma cultura política feminista. Dando exemplos de outros países, onde as mulheres haviam conquistado direitos políticos, diz que o Brasil "[...] não se pode[ria] furtar ao concerto das nações cultas" (A Notícia, 1931, p. 3). Não é difícil imaginar as reações às pretensões de igualdade das feministas. Embora afirme não querer a "revolução", seu discurso questiona o lugar de subordinação em que se colocavam as mulheres na cultura de forte ranço patriarcal.

Martha de Hollanda trabalhou "[...] ardorosamente com a pena e com a palavra", como diz o Diário da Noite, em prol da causa feminista (Diário da Noite, 1931, p. 3). Em outubro de 1931, no calor do debate sobre a reforma eleitoral prometida pelo governo provisório de Getúlio Vargas, que alguns já alcunhavam de "ditatorial" (Diário da Noite, 1931, p. 3), enviaIhe um memorial (Diário da Noite, 1931, p. 3) em nome da Cruzada Feminista Brasileira no qual pede para que o voto feminino seja concedido sem restrições (Jornal do Brasil, 1931, p. 10). Este seria o papel da República nova, inaugurada pelos revolucionários: promover a liberdade e a justiça para a mulher patrícia. Esperava, portanto, do novo governo, que cumprisse suas promessas de campanha. ${ }^{4}$

Para além da campanha pela emancipação política das mulheres nos jornais, a Cruzada atuou em duas frentes, no ano de 1931: na expansão de núcleos em cidades do interior de Pernambuco, como noticiou o Jornal do Brasil, na seção Notícias de Pernambuco (Jornal do Brasil, 1931, p. 10), e na ação de cunho caritativo, com arrecadação de donativos para viúvas pobres, foco da nossa análise.

${ }^{3}$ Clóvis Beviláqua (1859-1944) foi jurista, legislador, professor e historiador. Foi autor do projeto do Código Civil brasileiro de 1900, consultor jurídico do Ministério das Relações Exteriores durante 28 anos, e também um dos fundadores da Academia Brasileira de Letras. Era membro do Instituto Histórico e Geográfico e teve relevante papel no debate em torno dos direitos políticos às mulheres. Cf.: http://www.e-biografias.net/clovis bevilaqua/. Acesso em: 20 mar. 2014.

${ }^{4}$ Por essa época, também enviou memorial ao governo português em prol de mais liberdade às mulheres lusitanas com a reformulação da lei eleitoral, em que havia "odiosas restrições" à participação política das mulheres. Cf. Jornal Pequeno, 1932. p. 1. 


\section{A Cruzada Feminista e o raid de caridade em prol das viúvas}

Uma das ações da Cruzada que ganhou a simpatia da imprensa pela causa foi o recolhimento de donativos para as viúvas necessitadas. As militantes da Cruzada distribuíram caixas em repartições públicas, docas, foro, palácio da justiça (A Notícia, 1931, p. 1) e em casas comerciais, para arrecadação de "óbolos" para viúvas pobres, cuja coleta seria feita mensalmente e distribuída no Natal, em momento festivo (Jornal do Brasil, 1931, p. 10). Para viabilizar a festa sem ônus para as sócias, em nome da Cruzada, Martha solicitou ao interventor federal em Pernambuco, Carlos de Lima Cavalcanti, ${ }^{5}$ que concedesse gratuitamente o Teatro do Parque para que pudesse realizar o festival em nome das viúvas desamparadas (HOLLANDA, 25/06/1932). Por razões que nos escapam, a festa não aconteceu em dezembro, como desejavam as feministas.

Sabe-se que a campanha de donativos continuou com força e propaganda na imprensa escrita. Em notas curtas no Jornal Pequeno, quase como panfletos, Martha de Hollanda conclama as mulheres a irem até a porta da Cruzada Feminista Brasileira "[...] jogar uma flor de caridade sobre os destinos nevoentos das viúvas abandonadas" (Jornal Pequeno, 1932, p. 1). Em outra, dizia: "Acompanhe a Cruzada Feminista Brasileira, pedindo, de porta em porta, luz para as choupanas das viúvas deserdadas" (Jornal Pequeno, 1932, p. 1). Não exagerava no tom. Parte da população do Recife, em torno de $30 \%$, morava mesmo em mocambos, habitações rústicas e anti-higiênicas, construídas nos manguezais e em forma de palafitas (Manoel ANDRADE, 2007, p. 327). Segundo Lira, em 1932, a partir do exame da planta da cidade, os mocambos não só "[...] cercavam a cidade como um babado", como estavam "[...] enquistados em áreas mais urbanizadas" (Apud Virgínia PONTUAL, 2001. p. 33). Eram áreas insalubres, ocupadas a partir de necessidades múltiplas, da forte migração rural e sem a intervenção ou ordenamento do poder público, a ponto de a capital receber o epíteto de Mucambócolis (Zélia GOMINHO, 1998, p. 3, nota 3). Nesses mocambos, "[...] famílias se aboletavam em espaços mínimos com pouca ventilação, sendo denunciados como perigosos focos de doenças, como a tuberculose" (GOMINHO, 1998, p. 3). Campanhas como essa da Cruzada Feminista, sem dúvida, mobilizavam os sentimentos e as práticas caritativas de homens e mulheres de forte tradição católica, tão comuns e presentes no cotidiano da cidade.

Essa movimentação foi até intitulada como um raid de caridade, palavra em voga na época, para assinalar a ideia de corrida com etapas, para ajudar as viúvas e pobres mães desamparadas (Jornal Pequeno, 1932, p. 1), com final previsto para o dia 30 de janeiro. Assim, o jornal publica quase todos os dias doações e ações da Cruzada, com ênfase na figura obstinada de Martha de Hollanda. Participante ativo deste raid, o Jornal Pequeno comunica que a Cruzada ganhou do Dr. João Cleofas, secretário de Viação, Agricultura, Indústria, Comércio e Obras Públicas, atendendo a um pedido da escritora Martha de Hollanda, cinco sacas de café que foram enviadas das Docas do Porto até a sede da Cruzada (Jornal Pequeno, 1932, p. 1).

Outro feito dessa campanha está na propaganda que Martha conseguiu gratuitamente da firma M. G. Ferreira, cessionária dos serviços de anúncios da tranvia Tramways. ${ }^{6}$ Em quase todos os modernos bondes de trens da companhia inglesa que

\footnotetext{
${ }_{5}^{5}$ Sobre Carlos de Lima Cavalcanti, Cf. http://cpdoc.fgv.br/producao/dossies/AEraVargas1/biografias/ carlos de lima cavalcanti. Acesso em: 13/04/2014.

- The Pernambuco Tramways \& Power Company Limited foi uma empresa inglesa criada em 24 de janeiro de 1913, em Londres, com a finalidade de instalar e operar linhas de bondes elétricos no Recife, Pernambuco. Monopolizava os serviços de força e luz elétrica, de transportes urbanos e de gás encanado. PONTUAL, 2001. p. 31, nota 5
}

8 Revista Estudos Feministas, Florianópolis, 26(2): e44481 
atuava em Pernambuco, foi afixada a propaganda: "Vinde pelas mãos da Cruzada Feminista Brasileira minorar o desconforto das viúvas desamparadas" (Jornal Pequeno, 1932, p. 2).

No dia 30 de janeiro, o jornal publica a notícia, com uma foto de Martha de Hollanda e o nome da Cruzada Feminista Brasileira, e informa que, na sede da Cruzada, foram abertas as caixas trazidas dos diversos estabelecimentos, conferidas as doações e registradas pela secretária, Mme. Dr. Mario de Castro, e que a entrega seria realizada às três horas da tarde, na Associação dos Empregados no Comércio (Jornal Pequeno, 1932, p. 1). As viúvas, em número de oitenta, foram matriculadas na Cruzada. Um grupo de viúvas recebeu $20 \$ 000$ em envelope, meio quilo de café e cortes de fazenda, e outra parte ganhou cortes de fazenda e uma pequena quantia em dinheiro (A Notícia, 1931, p. 3), terminando assim, com muito êxito, a campanha empreendida por Martha e suas companheiras. Assim, como assinala Michelle Perrot, para a coleta de fundos ou bazars promovidos pela Ladie's sale em Londres, as feministas aqui e lá faziam passar uma mensagem política sob a cobertura da festa (PERROT, 2005, p. 282). Ao fazer uma campanha como essa, a Cruzada terminou por chamar a atenção dos poderes públicos para os problemas que atingiam essas mulheres e sua prole, duplamente desamparadas. Alia-se a isso a ampla preocupação com a infância pobre e abandonada nas décadas iniciais da República, que deu origem ao Código de Menores de 1927 (BRASIL, 1927; James WADSWORTH, 1999. p. 103).

A campanha, por mais centrada que tenha sido na figura de Martha, serviu para divulgar, dar visibilidade à Cruzada Feminista Brasileira, figurando como uma estratégia para ampliar a filiação de mulheres, nesse caso, mulheres pobres, provavelmente analfabetas e sem um homem para antepor-Ihes a vontade. Todavia, ainda que a via de assimilação tenha sido a assistência caritativa, prática conhecida e de longo lastro social e conservador, pode ter preocupado os governantes e a lgreja Católica, pela persuasão de mulheres pobres, vistas como desprotegidas da tutela masculina, ingressando em um movimento que lutava por igualdade entre os gêneros, inclusive, no campo da educação e dos direitos políiticos.

É possível, sim, que a Cruzada Feminista Brasileira tenha ficado mais conhecida na cidade, alcançando mulheres e homens letrados e não letrados, sobretudo quando ganha os trens da Tramways e, mais ainda, com a figura da feminista Martha de Hollanda, que a cidade conhecia cada vez mais. Contudo, o movimento que liderou, mostrou, logo cedo, suas fissuras internas, e o feminismo em Pernambuco estava mesmo fervendo, como noticiou o jornal Diário de Notícias do Rio de Janeiro, em setembro de 1932.

\section{E o feminismo pernambucano está fervendo...}

Ainda não existe organizado o feminismo no Brasil, e já as feministas andam brigando. Há pouco, foi aqui no Rio, onde as hostes se cindiram por motivo do projeto da Constituição. Havia duas candidatas, e as coisas só se acomodaram porque o governo resolveu contentar "tout le monde et sa mére". Agora a briga feminista é em Pernambuco. A Cruzada Feminista Brasileira realizou uma sessão para injuriar certa consocia que, por isso, deu queixa-crime contra a presidenta. E o feminismo pernambucano está fervendo... (Diário de Notícias, 1932, p. 3).

É assim que o Diário de Notícias do Rio de Janeiro informa aos/às eleitores/as divergências e os conflitos do movimento feminista no Brasil e em Pernambuco, em setembro de 1932, quando as mulheres já haviam alcançado, depois de muita luta, o direito ao voto. O periódico publica uma nota pequena na qual opina que o feminismo no Brasil nem está tão organizado assim, e as feministas já "andam brigando". Embora não explique em detalhes, reporta-se ao Rio de Janeiro, onde a cisão se deu por conta da composição para a Comissão de Elaboração do Anteprojeto da Constituição, com duas candidatas feministas e Getúlio 
Vargas na condução do governo provisório. Segundo a nota, Vargas "[...] resolveu contentar 'tout le monde et sa mére"', isto é, terminou por nomear as duas representantes: Bertha Lutz e Nathércia Silveira. ${ }^{7}$ Depois, o articulista comenta que a Cruzada Feminista Brasileira realizou uma sessão para "[...] injuriar certa consocia que, por isso, deu queixa-crime contra a presidenta". Termina por concluir que "[...] o feminismo pernambucano está fervendo", e não é exagero do Diário.

As feministas da Federação Brasileira para o Progresso Feminino, sob a liderança de Bertha Lutz, enfrentavam, naquele momento, um racha político, com a saída de Nathércia Silveira da referida associação e a criação de outra organização, a Aliança Nacional de Mulheres, sob sua liderança e com maior inserção no operariado feminino (ALVES, 1980, p. 122-126). Em Pernambuco, a Cruzada Feminista Brasileira estava mesmo em pé de guerra, com uma ação judicial movida por Martha de Hollanda contra as companheiras, contenda essa que ganhou as páginas dos periódicos locais e nacionais.

Embora Bertha Lutz tentasse manter o discurso da unidade do movimento feminista em todo o Brasil, seu jogo discursivo fazia parte de uma estratégia de silenciar as dissidências internas, as oposições e as opiniões divergentes das suas. No Rio de Janeiro e no Recife, as feministas fundaram diferentes núcleos e/ou associações. Mobilizaram grupos de mulheres na capital, nos subúrbios e cidades do interior. Por diferentes motivos, disputaram a liderança das organizações, foram contestadas, embora nem sempre, ao separarem-se, assumissem posições políticas profundamente divergentes entre si (Sobre a disputa entre Bertha Lutz e Nathércia Silveira pela liderança na FBPF (cf. PINTO, 2003. p. 26). Em ambas as cidades, as distensões internas ganharam as páginas da imprensa, ávida por notícias, indo na contramão do esforço feito pela líder feminista carioca de abafar as contendas internas.

A diferença crucial no caso da Cruzada Feminista Brasileira é que, pela primeira vez, vê-se publicada nos jornais a judicialização do conflito entre companheiras da luta feminista e a ruptura da amizade, que era o solo fértil dessa organização, como de outras congêneres no País. O estopim dessa contenda dá-se no momento em que se celebra o primeiro ano de criação da Cruzada Feminista Brasileira em solo pernambucano. No dia 29 de maio de 1932, a Sra. Celeste Dutra, na condição de presidenta em exercício, junto com Martha de Hollanda, Heloísa Chagas e outras companheiras, dirige-se para a Rádio Club de Pernambuco (Sobre a Rádio Club de Pernambuco, cf. Renato Phaelante da CÂMARA, 1998) para participar de uma programação radiofônica com duração de duas horas, indo das $20 \mathrm{~h}$ às $22 \mathrm{~h}$.

Nessa ocasião festiva, Martha de Hollanda, como líder do movimento, faz uma longa palestra dirigida aos/às poucos/as ouvintes da Rádio Club de Pernambuco (Jornal Pequeno, 1932, p. 1 e 4), tendo em vista o alcance diminuto e seletivo que tinha a rádio naquele momento. ${ }^{8}$ Em seu discurso, a feminista exibe erudição na larga tradição da retórica como sói pertencer às elites intelectuais deste período (José Murilo de CARVALHO, 2002, p. 123152). Apesar de não ter sido uma leitora ingênua da tradição católica e humanista que recebeu, o conhecimento que expressa é eivado de palavras pomposas e cultura bacharelesca, como se pode notar no primeiro parágrafo que abre sua fala:

\footnotetext{
${ }^{7}$ A ruptura entre as feministas se deu pelo apoio declarado de Nathércia Silveira à chapa da Aliança Liberal, composta por Getúlio Vargas e Epitácio Pessoa, em contraposição à decisão de neutralidade de Bertha Lutz, presidente da Federação Brasileira para o Progresso Feminino, na campanha eleitoral para a presidência do País em 1930. Ver ALVES, 1980. p. 122-126.

${ }^{8}$ A programação era mesmo para as elites, porque "[...] para captar as transmissões, eram necessários os aparelhos receptores, todos importados e, portanto, muito caros, o que fazia com que a programação se voltasse para as elites, ou seja, para quem pudesse pagar as contas do rádio". Cf. FREITAS, Goretti M. de, et al. 2015.
} 
Ad astra per aspera... E a legenda, justa e precisa, ficou como uma bandeira de vitória, dentro da terra lendária que escreveu a página rubente dos Guararapes e esconde o mistério encantado de Tejucupapo (Jornal Pequeno, 1932, p. 1).

É preciso mesmo trocar em miúdos esse palavreado. A expressão latina Ad astra per aspera, que significa por ásperos (caminhos) até aos astros, ${ }^{9}$ reduz o esforço das feministas da Cruzada no seu primeiro aniversário, uma legenda com vitórias que se somava ao passado de luta do povo pernambucano na expulsão dos holandeses, inclusive com a participação das mulheres, como foi a batalha de Tejucupapo. ${ }^{10}$

Apesar de o seu olhar iluminar as mulheres, retirá-las do silêncio e das sombras da história bíblica, da clássica ou da pernambucana, seu discurso é mesmo para intelectuais, mulheres e homens como ela, formados/as e com profissão. Como assinalou José Murilo de Carvalho, o discurso retórico precisa de respaldo, de autores clássicos, de autoridade para impressionar os seus pares (CARVALHO, 2002. p. 142). As referências longínquas se multiplicam no seu discurso num esforço de mostrar a força das mulheres: Martha manda rasgar a "Carta de Guia [de casados]" de D. Francisco Manuel, fidalgo português, publicada em 1651, em que, a partir de conselhos aos nubentes, advoga que as mulheres devem ser obedientes, submissas e iletradas para serem felizes. " Para a feminista, é preciso

[...] mostrar-lhe (a mulher) que o melhor livro lhe não é almofada e o bastidor, senão aquele em que se escreveram todas as grandes páginas da história da humanidade. $\mathrm{E}$ não são somente as folhas galantes de cavalaria e de amor, mas, também de sabedoria e civismo (Jornal Pequeno, 1932, p. 1).

Não à submissão e à obediência cega. Se entendermos o "livro" como uma metáfora, observa-se o apelo para que o conhecimento frutifique como sabedoria e a participação política, como civismo. Assim, propõe modelos femininos em que as mulheres deveriam se mirar:

[...] Não é Cleópatra, dominando Marco Antônio, para quem a cidade dos césares não valia um só beijo dela; é Aspásia, ensinando Retórica, na era de Péricles, e trazendo a seus pés a força formidável de Sócrates e Alcibíades (Jornal Pequeno, 1932, p. 1).

Trata-se mesmo de uma erudição ostentosa, sem dúvida. Demonstra um saber polido, sem ter frequentado os bancos da faculdade. Em seu discurso, que por vezes chega a tangenciar o ateísmo, contesta as santas em nome das guerreiras, conclama o amor entre os casais, ao reverenciar a proibida relação de amor entre o monge Abelardo e Heloísa.

Tendo como aporte homens de incontestável importância intelectual na época, como Rousseau e Eduard de Laboulauye, ${ }^{12}$ a autora ancora o pleito da Cruzada Feminista Brasileira. Para Martha, a Cruzada "[...] não desadora o sonho", essa organização pleiteia "[...] seu justo lugar [da mulher] no concerto da humanidade". Retoma a História Antiga para dizer que, em Cartago, as mulheres também enfrentaram as hostes inimigas e conclama as mulheres brasileiras a armarem-se de ânimo e coragem:

${ }_{9}^{9}$ https://ciberduvidas.iscte-iul.pt/consultorio/perguntas/a-traducao-de-per-aspera-ad-astra/14360. Acesso em: $01 / 09 / 2015$.

${ }^{10} \mathrm{~A}$ Batalha de Tejucupapo diz respeito à luta das mulheres contra a invasão de holandeses a um pequeno vilarejo chamado Tejucupapo, no litoral norte do Estado de Pernambuco, em 1646. Disponível em: http:/l www.onordeste.com/onordeste/enciclopediaNordeste/index.php?titulo=Batalha+de+Tejucupapo, +Pernambuco \&ltr=b\&id perso=2370. Acesso em: 10/09/2015.

"Disponível em: http://www.uc.pt/uid/celga/recursosonline/cecppc/textosempdf/05cartadeguiadecasados. Acesso em: 20/03/2014

12 Édouard René de Laboulaye Lefèvre, historiador, jurista, poeta, abolicionista, é lembrado como autor intelectual da Estátua da Liberdade. Cf. Disponível em: http://www.college-de-france.fr/media/lettre-du-collegede-france/UPL38565_J26LABOULAYE.pdf. Acesso em: 26/03/2014. 
[...] e, com esforço útil e proveitoso, destruir os últimos redutos dos preconceitos que nos fizeram desmerecer as mulheres do passado. Todas as artes, todas as ciências, todos os ofícios têm lugar para nós. A atividade abre-nos todas as portas (Jornal Pequeno, 1932, p. 1).

Para que mulheres discursava essa jovem feminista? Até hoje seu discurso parece distante das agruras do cotidiano, da labuta, da violência que marcava as relações entre os gêneros, do trabalho difícil para tantas mulheres que não tinham marido ou família de posses para sustentá-las, como era a situação das viúvas pelas quais fez campanha (Sobre a situação das mulheres pobres e trabalhadoras no Recife, ver PEREIRA, 2015). Falava para pessoas que, como ela, tiveram acesso à educação formal, família ilustre e situação financeira confortável. Mulheres e homens das camadas médias e abastadas. Imagino que também enfrentava a crítica masculina. Os poetas, os literatos, os intelectuais de seu circuito pessoal, onde se cultuava a retórica como "elemento de autoridade", como ressalta Carvalho (2002, p.142).

O que se sucede depois dessa palestra ainda é obscuro. Sabe-se que Martha de Hollanda abriu queixa-crime por infâmia e injúria contra as companheiras da Cruzada Feminista Brasileira. Em carta enviada à Cruzada, Martha afirma que "[...] nada teria contra a decisão de antigas companheiras, se não fora a medida sub-reptícia, vexatória e injusta de sua ação", o que a obrigava a agir em nome de sua honra, "[...] gravemente afetada pela descortesia que se premeditou e realizou" na sua ausência (HOLLANDA, 25/06/1932). Segundo a missiva, pode-se compreender que, em assembleia extraordinária, Martha de Hollanda foi destituída do cargo da presidência da associação, cuja decisão ela não aceitou.

A contenda foi mesmo parar na Justiça, e os jornais noticiaram com gozo e frequência o imbróglio (Jornal da Noite, 1932, p. 2); em geral, notícias favoráveis a Martha de Hollanda. Alguns vaticinavam e lamentavam, e com razão, que o dissídio "aniquila[va]" a Cruzada Feminista pelo afastamento "[...] da sua figura de maior relevo" (Jornal da Noite, 1932, p. 2). Já Edwiges de Sá temia que esses acontecimentos não se limitassem ao "desprestígio" das mulheres envolvidas na Cruzada, mas se espraiassem à "causa feminista", que seria "[...] rudemente atingida na expressão genérica: feminismo". Se isso aconteceu, não sabemos (SÁ PEREIRA, 13/09/1932)

Martha de Hollanda foi a liderança que mais ganhou visibilidade na mídia impressa e falada. A campanha para donativos às viúvas, como vimos, foi centrada na instituição e no nome de Martha de Hollanda, uma campanha personalizada. Talvez tenha gerado disputas internas e olhares desconfiados. Até onde foi possível chegar, ficou clara a ruptura e a contestação de sua liderança no episódio, um tanto obscuro, do aniversário da Cruzada. A "companheira incendiária", como se intitulou numa carta à Bertha Lutz, ainda em 1928 (HOLLANDA, 9/07/1928) posicionou-se publicamente a favor do divórcio, tema explosivo na época, tal como hoje é o aborto e, neste sentido, fez mesmo o feminismo ferver em Pernambuco. Pagou caro pela franqueza; pela forma de vestir-se, ousada demais para a época; por receber em sua casa, nas tertúlias e nos saraus que promoveu com seu marido na Rua do Lima, já no Recife, a nata dos intelectuais, quase sempre homens, para conversas literárias e políticas, regadas a whisky, licores e saborosos quitutes dos quais nos fala sua biógrafa (Luciene FREITAS, 2003). Teceu para si uma estética da vida, aproximando a política da poesia e da literatura. Publicou o Delírio do Nada em 1930, livro que projetou seu nome no Brasil e fora das fronteiras nacionais. Tornou-se conhecida e falada.

Nesse debate complexo e paradoxal pela igualdade com os homens na constituição do sujeito feminino do direito e na configuração de uma identidade feminina de feição moderna, chama atenção o silêncio em torno das mulheres negras e indígenas. Nada se diz sobre o racismo, bem como estão ausentes as demandas específicas das mulheres 
trabalhadoras e operárias das ruas e das fábricas. Esse feminismo tem classe. É conduzido por mulheres de classe média e abastada e acredita na via liberal para a conquista e ampliação da cidadania, cujas práticas políticas não foram tão "incendiárias" como fez supor sua líder.

Mas foi esse pequeno grupo de mulheres, nem sempre de tez clara, unidas pela amizade e por ideais, como Martha, Heloísa, Auri, Celeste, Juracy, Antônia, dentre outras, que enfrentou, por vezes, suas famílias, a chacota, o antifeminismo disseminado na cultura e na imprensa; expandiu as exigências da equidade; questionou as diferentes assimetrias e limitações da República liberal e tão pouco democrática; contestou a naturalização da diferença entre os sexos; e lutou pela ampliação da cidadania e da democracia em solo pernambucano. Do legado dessas lutas feministas, pouco conhecido na História, todas nós somos beneficiárias.

\section{Agradecimento}

Gostaria de agradecer ao CNPq o financiamento desta pesquisa intitulada "E o feminismo ferve em Pernambuco! Os Movimentos Feministas em Recife em luta pela Cidadania e Educação das Mulheres (1920-1934)", projeto n. 40481220120, vigência: 2013-2015.

\section{Referências}

AGUIAR, Neuma. "Patriarcado, sociedade e patrimonialismo". Sociedade e Estado. [online]. 2000 , v. 15 , n. 2 , pp. 303-330. http://www.scielo.br/scielo.php?pid=s010269922000000200006\&script=sci_arttext. Acesso em 12/05/2015

ALBUQUERQUE JR. Durval Muniz de. A invenção do Nordeste e outras artes. 4. ed. Recife: FJN; Massangana; São Paulo: Cortez, 2009.

ALVES, Branca Moreira. Ideologia e feminismo: a luta da mulher pelo voto no Brasil. Petrópolis: Vozes, 1980.

ANDRADE, Manoel Correia. Pernambuco imortal. Recife: Companhia Editora de Pernambuco, 2007.

A NOTíCIA. Recife, 31/01/1931. p. 1. Recife, 31/05/1931, p. 1.

. Recife, 03/07/1931, p. 1. . Recife, $31 / 07 / 1931$, p. 1. Recife, 08/08/1931, p. 3. Recife, 13/11/1931, p. 1.

A NOITE. Rio de Janeiro, 02/06/1931. p. 2.

BARBOSA, Marialva. "Imprensa, poder e público". Intercom. Revista Brasileira de Comunicação. São Paulo, v. 20, n. 2, p. 87-102, jul./dez, 1997.

BERSTEIN, Serge. "Cultura Política". In: RIOUX, Jean Pierre \& SIRINELLI, Jean François (org.). Para uma história cultural. Lisboa: Estampa, 1988. p.349-363.

BRASIL. Leis e Decretos. Decreto n. 17.943, de 12/10/1927. 1927. Consolida as leis de assistência e proteção a menores. Disponível em http://www2.camara.leg.br/legin/fed/ decret/1920-1929/decreto-1 7943-a-12-outubro-1927-501820-publicacaooriginal-1pe.html.

CÂMARA, Renato Phaelante da. Fragmentos da história do Rádio Clube de Pernambuco. Recife: Cepe, 1998.

CARVALHO, José Murilo de. "História intelectual no Brasil: a retórica como chave de leitura." Topoi: Revista de História, Rio de Janeiro, v.1, n. 1 p. 123-152. dez. 2002. 
COELHO, Nely Novaes. Dicionário crítico de escritoras brasileiras. São Paulo: Escrituras, 2002.

DIÁRIO DA NOITE. Rio de Janeiro, 28/10/1931. p. 3.

DIÁRIO DE NOTíCIAS. Rio de Janeiro, 04/09/1932. p. 3.

ESTATUTO da Federação Brasileira para o Progresso Feminino. Rio de Janeiro: Oficinas Gráficas do Jornal do Brasil, 1930. Arquivo Nacional. Fundo FBPF.

FERREIRA, Aurélio B. de H. Novo Dicionário Aurélio da Língua Portuguesa. 2. ed. Rio de Janeiro: Nova Fronteira, 1986.

FREITAS, Luciene. Uma guerreira no tempo: resgate de uma época, Martha de Hollanda e Delírio do Nada. Recife: 2003.

FREITAS, Goretti M. de et al. O que é preciso ler para entender o rádio e compreender o radialismo. In: CONGRESSO BRASILEIRO DE CIÊNCIAS DA COMUNICAÇÃO, 35ª edição, Rio de Janeiro. Anais, Rio de Janeiro. Intercom - Sociedade Brasileira de Estudos Interdisciplinares da Comunicação, 2015, p. 5. Disponível em: http://www.intercom.org.br/ sis/2012/resumos/R7-0178-1.pdf. Acesso em: 3/11/2015.

GOMINHO, Zélia de Oliveira. Veneza Americana x Mucambópolis - O Estado Novo na cidade do Recife (décadas de 30 e 40). Recife: Cepe, 1998.

HOLLANDA, Martha. Delírio do Nada. Recife: Imprensa Industrial, 1930. Carta a Bertha Lutz. Acervo do Instituto Histórico, Geográfico de Vitória de Santo Antão (IHGVSA). [s.d.] . Carta à Diretoria da Cruzada Feminista. Recife, 25/06/1932. Acervo do Instituto Histórico, Geográfico de Vitória de Santo Antão (IHGVSA). . Carta à Carmem Portinho. Vitória, 29/07/1928. Arquivo Nacional. Fundo FBPF. ADM, COR. 1928.147.

JORNAL DO BRASIL. Rio de Janeiro, 09/08/1931. p. 3 e p. 10.

JORNAL DA NOITE. Recife, 17/09/1932. p. 2.

JORNAL PEQUENO. Recife, 15/01/1932. p. 1; Recife, 16/01/1932, p. 1. . Recife, 23/01/1932, p. 1. Recife, 26/01/1932, p. 2. Recife, 27/01/1932, p. 1. Recife, 30/01/1932, p. 1. Recife, 28/05/1932, p. 1. Recife, 31/05/1932, p. 1 e p. 4.

MARTINS, Ana L.; LUCA, Tânia Regina de. Imprensa e cidade. São Paulo: Ed. Unesp, 2006. MATTOS, Hebe. "A vida política". In: SCHWARTZ, Lilia Moritz (Coord.). Abertura para o mundo. v. 3. Madrid/RJ: Fundação Mapfre/Objetiva, 2012. p. 85-131.

MOTTA, Rodrigo Patto Sá. "Desafios e possibilidades na apropriação de cultura política pela historiografia". In: MOTTA, Rodrigo Patto Sá (org.) Culturas Políticas na História: novos estudos. Belo Horizonte, MG: Argvmentvm, 2009. p. 13-37.

"A história política e o conceito de cultura política". LPH: Revista de História. n. 6, 1996 p.92-100. Disponível em: http://www.ichs.ufop.br/lph/images/stories/numero_6.pdf. Acesso em: 12/08/2015

NASCIMENTO, Alcileide Cabral. "O bonde do desejo: o Movimento Feminista no Recife e o debate em torno do sexismo (1927-1931)". Revista Estudos Feministas, Florianópolis, v. 1, n. 21, p. 41-57, jan./abr. 2013.

"Martha de Hollanda and the Brazilian Feminist Crusade (1928-1932): an 'inflammatory feminist' in Pernambuco?" Labrys, études féministes (Estudos Feministas) Brasília, v. 27, jan./jun, 2015, p. 1-11.

14 Revista Estudos Feministas, Florianópolis, 26(2): e44481 
NASCIMENTO, Alcileide Cabral; LUZ, Noemia M. Q. Pereira da. "Liberdade, transgressão e trabalho: o cotidiano das mulheres na cidade do Recife (1870-1914)". Revista Territórios e Fronteiras, Cuiabá-MT, v. 1, n. 1, p. 126-149, 2012.

NASCIMENTO, Alcileide Cabral; MELO, Alexandre. "Melindrosas em revista: gênero e sociabilidades do início do século XX (Recife, 1919-1929) “. In: História Revista. Goiânia, n. 3, v. 19, 2014. p. 6-20. Disponível em: https://www.revistas.ufg.br/historia/search/ search?simpleQuery=alexandre+melo\&searchField=query

PEREIRA, Viviane Barbosa. Outros trabalhadores: experiências e cotidiano de trabalho de homens e mulheres no Recife (1890-1915). 2015 Dissertação (Mestrado em História) Programa de Pós-Graduação em História, Universidade Federal Rural de Pernambuco, Recife, PE, Brasil.

PERROT, Michelle. As mulheres ou os silêncios da história. Bauru, SP: EDUSC, 2005.

PINTO, Céli Regina Jardim. Uma história do feminismo no Brasil. São Paulo: Ed. Perseu Abramo, 2003.

PONTUAL, Virgínia. Uma cidade e dois prefeitos. Narrativas do Recife nas décadas de 1930 a 1950. Recife: Ed. UFPE, 2001.

SÁ PEREIRA, Edwiges de. Carta à Bertha Lutz. Recife, 13/04/1927. Arquivo Nacional. Fundo FBPF. ADM, COR. 1927.48

Carta à Bertha Lutz. Recife, 13/09/1932. Arquivo Nacional. Fundo FBPF. ADM, COR. 1932.66

Notas Biobibliográficas, Acervo Pessoal. Recife, Fundação Joaquim Nabuco (FUNDAJ), [s. d.]

SALIBA, Elias T. "A dimensão cômica da vida privada na República". In: SEVCENKO, Nicolau (Org.). História da Vida Privada no Brasil. v.3. São Paulo: Cia das Letras, 2002. p. 289-365.

SCHUMAHER, Schuma; BRAZIL, Érico Vital. Dicionário mulheres do Brasil: de 1500 até a atualidade. Rio de Janeiro: Zahar, 2000.

SEVCENKO, Nicolau. Literatura como missão: tensões sociais e criação cultural na Primeira República. São Paulo: Brasiliense, 1985.

SILVA, Soraia Maria. Poemadançando: Gilka Machado e Eros Volúsia. Brasília: Ed. UnB, 2007.

SINEAU, Mariette. "Femmes et culture politique. Nouvelles valeurs, nouveaux modèles?" In: Vingtième Siècle. Revue d'histoire. $n^{\circ} 44$, Paris, Presses de Sciences Po, oct.-déc, 1994. p. 72-78.

SOIHET, Rachel. O feminismo tático de Bertha Lutz. Florianópolis: Mulheres; Santa Cruz do Sul: Edunisc, 2006.

UCHÔA, Ida Souto. Discurso na solenidade de criação da FPPF. Recife, 10/1 1/1931. Arquivo Nacional, Fundo FBPF.

WADSWORTH, James. "Moncorvo Filho e o problema da infância: modelos institucionais e ideológicos da assistência à infância no Brasil." In: Revista Brasileira de História, n. 37. São Paulo: Associação Nacional de História, 1999. p. 103-124.

[Recebido em 26/04/2016 e aprovado em 17/08/2016]

The Brazilian Feminist Crusade and political culture in Pernambuco (1927-1932)

Abstract: This article is an investigation of the importance of the Brazilian Feminist Crusade, a creation of Martha Hollanda in 1931, in the construction of a new feminist political culture in which women debate gender inequality and struggle for egalitarian rights between the years of 1927 and 1932. The Brazilian Feminist Crusade made a strategic use of newspapers as the main mass 
medium at the time when the female subject of law was instituted and daily newspapers formed a public opinion. The feminists enlarged the scope of the demands for equality, called into question the different asymmetries of a Republic that was liberal and short on democracy, they contested the naturalization of the difference between the sexes and fought for the widening of citizenship and democracy in the soil of Pernambuco. We are, all of us, the beneficiaries of these feminist struggles, so little known to History.

Keywords: Brazilian Feminist Crusade; Martha de Hollanda; Feminist Political Culture

Alcileide Cabral Nascimento (alcileide.cabral@gmail.com) é pós-doutora pela UNICAMP- SP (2011) e Universidade Federal Fluminense - UFF (2017) e doutora em História pela Universidade Federal de Pernambuco (2006). Os temas de pesquisa atuais: História do Movimento Feminista; Feminismos; Relações de Gênero; Maternidade; Infância e Políticas Públicas para Infância. Coordena o Grupo de Pesquisas e Estudos em Gênero (NUPEGE/ UFRPE); integra o GT Nacional de Relações de Gênero e o GT Infância e Juventude/ANPUH PE.

16 Revista Estudos Feministas, Florianópolis, 26(2): e44481 